\title{
Novel and Reusable Mesoporous Silica Supported 4-Methylbenzenesul- fonate-functionalized Ionic Liquids for Room Temperature Highly Efficient Preparation of 2,4,5-Triaryl-1 $\mathrm{H}$-imidazoles
}

\author{
Yang Liu ${ }^{1}$, Qi Rong ${ }^{1}$, Chen $\mathrm{Chen}^{2}, \mathrm{Yu}$ Lin $\mathrm{Hu}^{1}$ * \\ ${ }^{1}$ College of Materials and Chemical Engineering, Key laboratory of inorganic nonmetallic crystalline and \\ energy conversion materials, China Three Gorges University, Yichang 443002, P. R. China. \\ ${ }^{2}$ College of Environmental and Chemical Engineering, Jiangsu University of Science and Technology, \\ Zhenjiang 212003, P. R. China.
}

*Corresponding author: Yu Lin Hu, email: huyulin1982@163.com

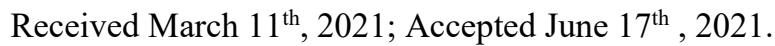

DOI: http://dx.doi.org/10.29356/jmcs.v65i4.1529

\begin{abstract}
A series of mesoporous materials supported ionic liquids were prepared and tested as effective and practical catalysts for the synthesis of 2,4,5-triaryl- $1 H$-imidazoles. The effects of type of catalysts, catalyst amount, and catalyst stability have also been investigated in detail, the catalyst Ti-SBA-15@ILTsO exhibited excellent activity in excellent yields of $92 \% \sim 99 \%$ with low catalyst amount at room temperature within $1 \mathrm{~h}$. In addition, the supported ionic liquid can be easily recovered and reused for six times with satisfactory catalytic activity. Furthermore, a general synergetic catalytic mechanism for the reaction was proposed. Maybe this work employing Ti-SBA-15@ILTsO as highly efficient and stable catalyst for the synthesis of 2,4,5-triaryl-1Himidazoles has potential commercial applications.

Keywords: Mesoporous silica; supported ionic liquid; high efficient; 2,4,5-triaryl-1H-imidazoles; synergetic and recyclable catalyst.

Resumen. Se prepararon y probaron una serie de materiales mesoporosos soportados con líquidos iónicos como catalizadores eficaces y prácticos para la síntesis de 2,4,5-triaryl-1H-imidazoles. También se investigaron en detalle los efectos del tipo de catalizadores, la cantidad de catalizador y la estabilidad del catalizador. El catalizador Ti-SBA-15@ILTsO mostró una excelente actividad con rendimientos excelentes del $92 \%$ 99\% con una baja cantidad de catalizador a temperatura ambiente en $1 \mathrm{~h}$. Además, el líquido iónico soportado puede recuperarse fácilmente y reutilizarse durante seis veces con una actividad catalítica satisfactoria. Por otro lado, se propuso un mecanismo catalítico sinérgico general para la reacción. Este trabajo que emplea Ti-SBA15@ILTsO como catalizador altamente eficiente y estable para la síntesis de 2,4,5-triaril-1H-imidazoles puede tener aplicaciones potencialmente comerciales.

Palabras clave: Sílice mesoporosa; líquido iónico soportado; alta eficiencia; 2,4,5-triaril-1H-imidazoles; catalizador sinérgico y reciclable.
\end{abstract}

\section{Introduction}

Imidazole and their derivatives, especially 2,4,5-triaryl- $1 H$-imidazoles, are found to act as building blocks for the synthesis of many important drugs, herbicides, anticancer, and fine chemicals [1-4]. Thus, the synthesis of imidazole derivatives has attracted an immense interest in the field of organic synthesis. The 
classical method for the synthesis of 2,4,5-triaryl-1H-imidazoles involves the condensation of benzil, aldehyde and ammonium acetate in the presence of organic acids and Lewis acids catalysts [5-7]. However, these methods often suffered from low yields, harsh conditions, and tedious procedures. Over the past decades, a large number of catalysts have been reported for the synthesis of 2,4,5-triaryl- $1 \mathrm{H}$-imidazoles such as molecularly imprinted polymer [8], iodine/DMSO [9], $\mathrm{NiO}$ nanocomposites/rGO [10], $\mathrm{Fe}_{3} \mathrm{O}_{4} @ \mathrm{SiO}_{2} \cdot \mathrm{HM} \cdot \mathrm{SO}_{3} \mathrm{H}$ [11], Co complex@KCC-1 [12], CSNPs/MWCNT@ $\mathrm{Fe}_{3} \mathrm{O}_{4}$ [13], CAN [14], $\mathrm{Fe}_{3} \mathrm{O}_{4} @ \mathrm{CS}$ [15], dihydroquinoline [16], LADES@MNP [17], and others [18-20]. Unfortunately, most of these protocols still suffered from disadvantages such as the stoichiometric use of catalysts, high reaction temperatures, tedious isolation techniques, and catalyst recycle problems. In this regard, the development of novel, sustainable and efficient catalytic systems for the production of 2,4,5-trisubstituted imidazoles are highly recommendable.

Ionic liquids (ILs), as a charming functional material, have found numerous applications in various areas of reaction solvents and catalysis due to their negligible vapour pressure, thermal and chemical stability, non-flammable, nonvolatile, low toxicity and strong structural design prospects [21-25]. Through the functional design of anions and cations of ionic liquids, the use of ILs as catalysts in the efficient synthesis of 2,4,5-triaryl$1 \mathrm{H}$-imidazoles have been devoleped [26,27]. However, the isolation of pure ILs from products and reusability has been the major issue in these processes in view of eco-sustainability. Therefore, the immobilization of these functionalized ILs over different solid supports to explore heterogeneous supported ILs has made the process easier through their easy handling, thermal stability, facile isolation and reusability [28-33]. Among these soild supports, mesoporous silica materials offer significant advantages of large surface area, highly ordered structure, thermal and chemical stabilities. These materials can be used as a platform for the loading and dispersion of active components such as ILs or transition metals, thereby increasing their catalytic activities and have been widely utilized as supports in the case of heterogeneous catalysis [34-39]. Thus, the goal of this work is to design and synthesize a series of mesoporous SBA-15 and transition metals modified SBA-15 materials supported functionalized ionic liquids. These supported ionic liquids have been employed as recyclable and high-efficient heterogeneous catalysts for the product of 2,4,5-trisubstituted imidazoles under mild conditions (Scheme 1). Furthermore, the recycling performance of catalyst and possible catalytic mechanism were explored.

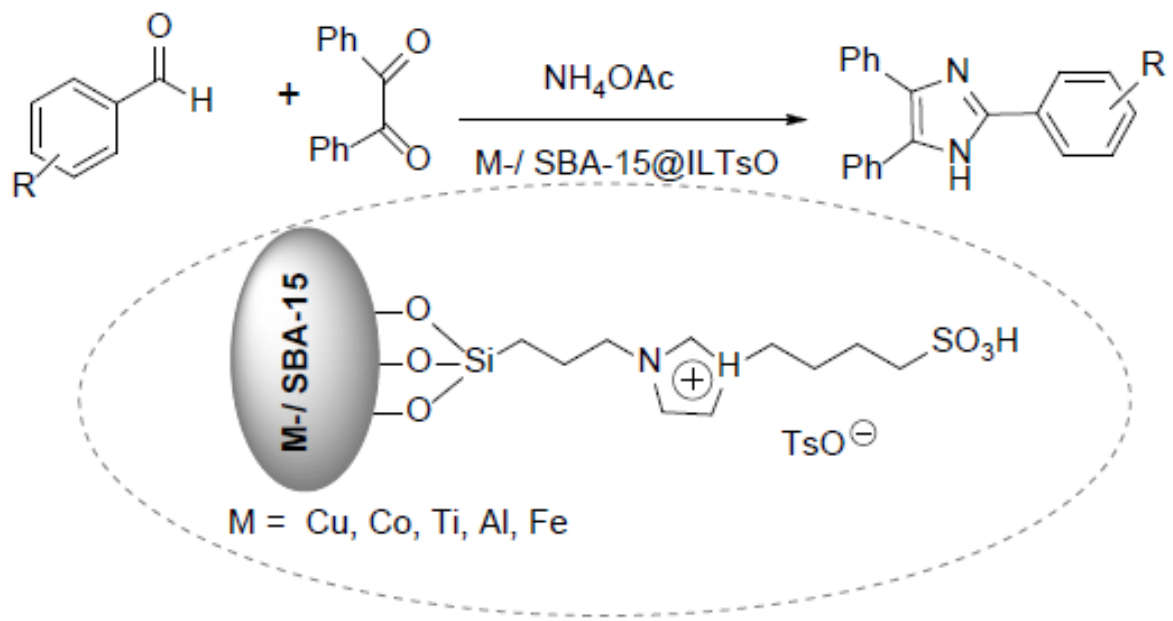

Scheme 1. Catalytic synthesis of 2,4,5-triaryl-1H-imidazoles in the presence of M-/ SBA-15@ILTsO. 


\section{Experimental}

\section{Materials And Methods}

$\mathrm{EO}_{20} \mathrm{PO}_{70} \mathrm{EO}_{20}$ (Pluronic 123) was purchased from Sigma-Aldrich. The remaining reagents were obtained commercially and were used with no further purification. FT-IR spectra were recorded on a PE Fourier Transform spectrophotometer. Scanning electron microscopy, energy dispersive X-ray spectroscopy (SEM, EDX) were performed on a JSM-7500F electron microscope. Powder X-ray diffraction (XRD) analysis was recorded by Ultima IV diffractometer. UV-Vis spectra were recorded by Shimadzu UV-2450 spectrophotometer. Thermogravimetric analysis was measured by a NETZSCH STA 449 F5 apparatus. $\mathrm{N}_{2}$ adsorption-desorption isotherms were carried out on a BELSORP-max apparatus. Melting points were measured by an electro-thermal IA 9100 apparatus. ${ }^{1} \mathrm{H}$ NMR spectra were recorded on a Bruker $400 \mathrm{MHz}$ spectrometer. LC-MS analysis were carried out on an Agilent 6410 instrument. The mass detector was set to positive electron ionization (EI) mode and the electron beam energy was $70 \mathrm{eV}$.

\section{Preparation of supported ionic liquids}

The schematic for the preparation of supported ILs is shown in Scheme 2. SBA-15 and M-SBA-15 (M $=\mathrm{Ti}, \mathrm{Al}, \mathrm{Cu}, \mathrm{Co}, \mathrm{Fe}$ ) were synthesized according to the procedures [34]. The supported ionic liquids catalysts were synthesized using the similar procedures [28-30,35]. A typical procedure was as follows: Sodium ethoxide $(0.2 \mathrm{~mol})$, ethanol $(200 \mathrm{~mL})$ and imidazole $(0.2 \mathrm{~mol})$ were stirred at $80{ }^{\circ} \mathrm{C}$ for $4 \mathrm{~h}$ to give a. Then $(3-$ chloropropyl) triethoxysilane $(0.2 \mathrm{~mol})$ was added, and the reaction mixture was refluxed for $24 \mathrm{~h}$. After evaporating the solvent, the mixture was washed with ethanol-water $(\mathrm{v} / \mathrm{v}=1 / 1,50 \mathrm{~mL})$ and dried under vacuum to afford $\mathbf{b}$. Subsequently, 1,4-butane sultone $(0.15 \mathrm{~mol})$, and $\mathbf{b}(0.15 \mathrm{~mol})$ were added to a $500 \mathrm{~mL}$ roundbottomed flask in the presence of toluene $(200 \mathrm{~mL})$. The reaction mixture was heated to $100{ }^{\circ} \mathrm{C}$ under nitrogen for $12 \mathrm{~h}$, thereafter, the solvent was isolated and dried to give $\mathbf{c}$. Next, $\mathbf{c}(0.1 \mathrm{~mol}), p$-toluenesulfonic acid $(0.1$ $\mathrm{mol})$, and toluene $\left(120 \mathrm{~mL}\right.$ ) were stirred at $80^{\circ} \mathrm{C}$ for $12 \mathrm{~h}$, then the solvent was evaporated, the obtained residue was washed with dichloromethane and then dried at $50{ }^{\circ} \mathrm{C}$ under vacuum to give ionic liquid $\mathbf{d}$ ILTsO. Finally, M-SBA-15 (M = Ti, Al, Cu, Co, Fe) or SBA-15 (2.0 g), and $\mathbf{d}(1.0 \mathrm{~g})$ were added to a solution of dry toluene $(150 \mathrm{~mL})$, and the mixture was stirred and refluxed for $24 \mathrm{~h}$ under nitrogen. The resulting solid was collected by filtration and washed with diethyl ether to remove excess IL. Then the above solid was dried under vacuum to afford the supported ILs e.

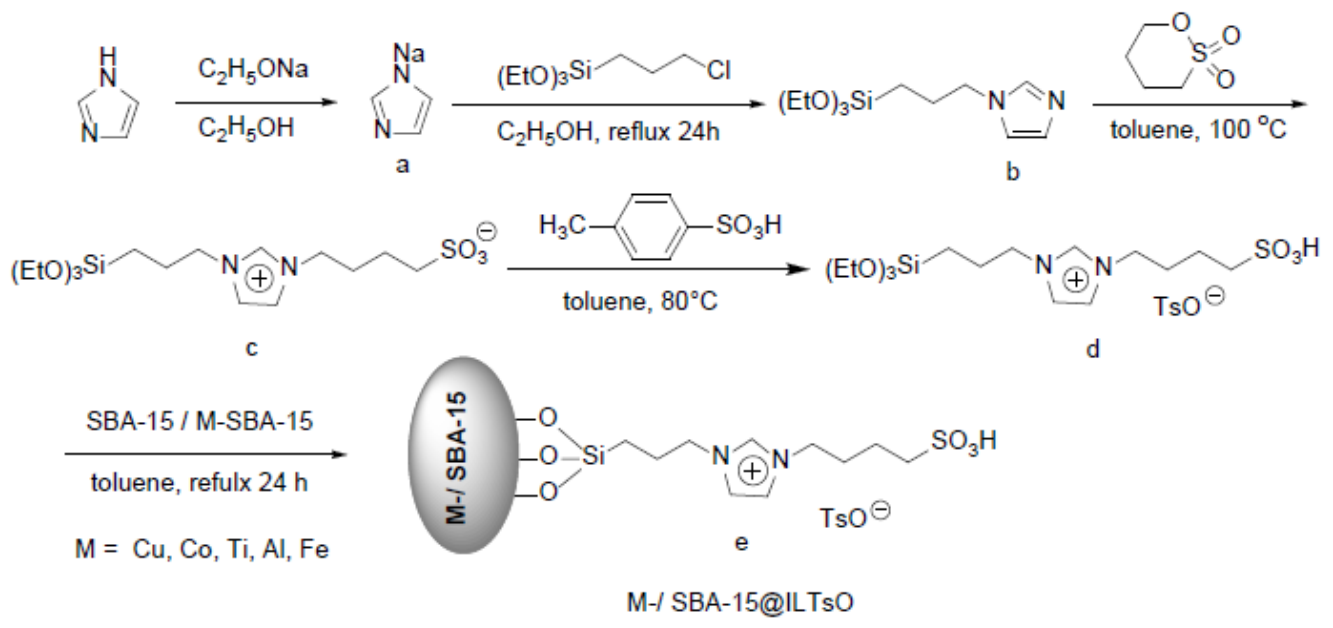

Scheme 2. Preparation of supported ionic liquids. 


\section{General procedure for catalytic reaction}

Aromatic aldehyde $(0.1 \mathrm{~mol})$, diphenylethanedione $(0.1 \mathrm{~mol})$, ammonium acetate $(0.2 \mathrm{~mol})$, Ti-SBA15@ILTsO (0.8 g), EtOH (30 mL) were added to a magnetically stirred three-neck flask. The reaction mixture was stirred at room temperature for the desired time. The reaction progress was monitored by TLC. After the reaction, the catalyst was filtered off and washed with ethanol and dried under vacuum. The filtrate was concentrated under reduced pressure and the crude product was purified by via recrystallisation with ethanol to give the corresponding pure product. Fresh substrates were then recharged to the recovered catalyst and then recycled under identical reaction conditions.

\section{Spectroscopic data for products}

2,4,5-triphenyl-1H-imidazole (Table 2, entry 1): White solid, mp 279.1-280.1 ${ }^{\circ} \mathrm{C}$; ${ }^{1} \mathrm{H}$ NMR (400 $\left.\mathrm{MHz} ; \mathrm{CDCl}_{3}\right)(\delta \delta / \mathrm{ppm}):$ 7.18-7.92 (m, 15H, Ar-H), 9.48 (s, 1H, NH); LC-MS: 297.0 [M+1].

4,5-diphenyl-2-(p-tolyl)-1H-imidazole (Table 2, entry 2): White solid, mp 239.0-239.2 ${ }^{\circ} \mathrm{C}$; ${ }^{1} \mathrm{H}$ NMR $\left(400 \mathrm{MHz}_{\mathrm{CDCl}}\right)(\delta \delta / \mathrm{ppm}): 2.38\left(\mathrm{~s}, 3 \mathrm{H}, \mathrm{CH}_{3}\right), 7.11-7.91(\mathrm{~m}, 14 \mathrm{H}, \mathrm{Ar}-\mathrm{H}), 9.62$ (s, 1H, NH) ppm; LC-MS: $311.0[\mathrm{M}+1]$.

4,5-diphenyl-2-(o-tolyl)-1H-imidazole (Table 2, entry 3): White solid, mp 256.9-257.5 ${ }^{\circ} \mathrm{C}$; ${ }^{1} \mathrm{H}$ NMR $\left(400 \mathrm{MHz} ; \mathrm{CDCl}_{3}\right)(\delta \delta / \mathrm{ppm}): 2.56\left(\mathrm{~s}, 3 \mathrm{H}, \mathrm{CH}_{3}\right), 7.08-7.89(\mathrm{~m}, 14 \mathrm{H}, \mathrm{Ar}-\mathrm{H}), 9.14(\mathrm{~s}, 1 \mathrm{H}, \mathrm{NH}) \mathrm{ppm}$; LC-MS: $311.0[\mathrm{M}+1]$.

2-(4-methoxyphenyl)-4,5-diphenyl-1H-imidazole (Table 2, entry 4): White solid, mp 234.3$236.3{ }^{\circ} \mathrm{C} ;{ }^{1} \mathrm{H} \mathrm{NMR}\left(400 \mathrm{MHz} ; \mathrm{CDCl}_{3}\right)(\delta \delta / \mathrm{ppm}): 2.47$ (s, 3H, $\left.\mathrm{OCH}_{3}\right), 7.06-7.97$ (m, 14H, Ar-H) ppm; LC-MS: $327.0[\mathrm{M}+1]$.

2-(4,5-diphenyl-1H-imidazol-2-yl)phenol (Table 2, entry 5): White solid, mp 199.4-202.5 ${ }^{\circ} \mathrm{C} ;{ }^{1} \mathrm{H}$ NMR (400 MHz; $\left.\mathrm{CDCl}_{3}\right)(\delta \delta / \mathrm{ppm}): 7.16-7.73$ (m, 15H, Ar-H), 8.19 (s, 1H, OH), 10.06 (brs, 1H, NH) ppm; LC-MS: $313.0[\mathrm{M}+1]$.

2-(2-chlorophenyl)-4,5-diphenyl-1 H-imidazole (Table 2, entry 6): White solid, mp 199.4-200.8 ${ }^{\circ} \mathrm{C}$; ${ }^{1} \mathrm{H}$ NMR (400 MHz; $\left.\mathrm{CDCl}_{3}\right)(\delta \delta / \mathrm{ppm}): 7.22-7.61$ (m, 13H, Ar-H), 8.43 (m, 1H, Ar-H), $10.33(\mathrm{~s}, 1 \mathrm{H}, \mathrm{NH}) \mathrm{ppm}$; LC-MS: $330.9[\mathrm{M}+1]$.

2-(4-chlorophenyl)-4,5-diphenyl-1H-imidazole (Table 2, entry 7): White solid, mp 269.2-270.2 ${ }^{\circ} \mathrm{C}$; ${ }^{1} \mathrm{H}$ NMR (400 MHz; $\mathrm{CDCl}_{3}$ ) $(\delta \delta / \mathrm{ppm}): 7.16-7.92$ (m, 14H, Ar-H), 9.41 (s, 1H, NH) ppm; LC-MS: 330.9 [M+1].

2-(2-nitrophenyl)-4,5-diphenyl-1 H-imidazole (Table 2, entry 8): Yellow solid, mp 238.4-239.4 ${ }^{\circ} \mathrm{C}$; ${ }^{1} \mathrm{H}$ NMR $\left(400 \mathrm{MHz} ; \mathrm{CDCl}_{3}\right)(\delta \delta / \mathrm{ppm}): 7.19-7.94(\mathrm{~m}, 13 \mathrm{H}, \mathrm{Ar}-\mathrm{H}), 8.41$ (m, 1H, Ar-H), 10.28 (s, 1H, NH) ppm; LC-MS: $341.9[\mathrm{M}+1]$.

2-(4-fluorophenyl)-4,5-diphenyl-1 H-imidazole (Table 2, entry 9): White solid, mp 259.6-260.2 ${ }^{\circ} \mathrm{C}$; ${ }^{1} \mathrm{H}$ NMR (400 MHz; $\left.\mathrm{CDCl}_{3}\right)(\delta \delta / \mathrm{ppm}): 7.11-7.68$ (m, 12H, Ar-H), 7.92 (m, 2H, Ar-H), 9.48 (s, 1H, NH) ppm; LC-MS: $315.0[\mathrm{M}+1]$.

4,5-diphenyl-2-(2-(trifluoromethyl)phenyl)-1H-imidazole (Table 2, entry 10): White solid, mp 261.4- 261.7 ${ }^{\circ} \mathrm{C} ;{ }_{1}^{1} \mathrm{H}$ NMR (400 MHz; $\left.\mathrm{CDCl}_{3}\right)(\delta \delta / \mathrm{ppm}): 7.12-7.81$ (m, 12H, Ar-H), 8.07-8.10 (m, 2H, Ar-H), 9.49 (s, 1H, NH) ppm; LC-MS: $364.9[\mathrm{M}+1]$.

\section{Results and discussion}

The composition and chemical bonding of supported ILs catalysts were investigated using FT-IR spectra (Fig. 1). The absorption bands observed at around $1087 \mathrm{~cm}^{-1}, 805 \mathrm{~cm}^{-1}$ were mainly due to the stretching vibration of $\mathrm{Si}-\mathrm{O}-\mathrm{Si}$. The absorption bands appeared about $3500-3375 \mathrm{~cm}^{-1}$ and $1651 \mathrm{~cm}^{-1}$ were related to the $\mathrm{H}-\mathrm{O}$ stretching and bending vibration. The characteristic absorption bands at around $1634 \mathrm{~cm}^{-1}, 1527 \mathrm{~cm}^{-1} \mathrm{were}^{-15}$ attributed as $\mathrm{N}=\mathrm{N}$, and $\mathrm{C}-\mathrm{N}$ stretching vibrations of imidazole ring [21-24]. The bands observed at around 2867 $\mathrm{cm}^{-1}, 1295 \mathrm{~cm}^{-1}$, and $738 \mathrm{~cm}-1$ were ascribed to the $\mathrm{CH}_{2}$ stretching vibration. The bands at about $975 \mathrm{~cm}^{-1}$, $1167 \mathrm{~cm}^{-1}, 798 \mathrm{~cm}^{-1}, 672 \mathrm{~cm}^{-1}$, and $964 \mathrm{~cm}^{-1}$ were belonged to Ti-O, Al-O, Cu-O, Co-O, Fe-O stretching vibration, respectively [34]. The bands at about $1603 \mathrm{~cm}^{-1}, 1496 \mathrm{~cm}^{-1}, 817 \mathrm{~cm}^{-1}$ were related to TsO vibrational mode [28]. 


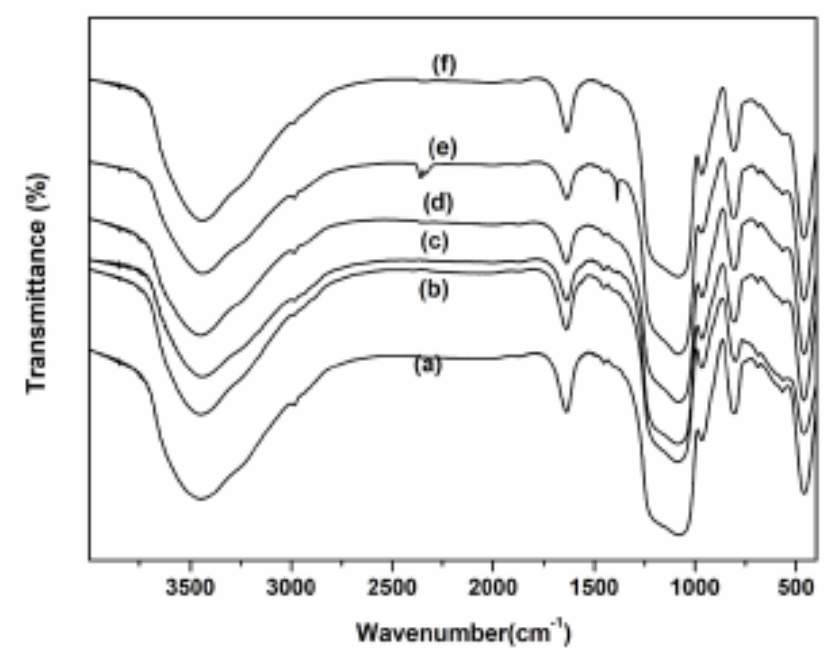

Fig. 1. FT-IR spectras of SBA-15@ILTsO (a), Ti-SBA-15@ILTsO (b), Al-SBA-15@ILTsO (c), Cu-SBA15@ILTsO (d),Co-SBA-15@ILTsO (e), Fe-SBA-15@ILTsO (f).

XRD patterns of the supported ILs catalysts are shown in Fig. 2. The characteristic band corresponding to (100) diffraction of ordered mesoporous structure was observed at about $2 \theta=22.1^{\circ}$, no additional bands of ILs were observed, maybe due to the reason of ILs sites well-dispersed onto the supports framework [34-36]. Figure 3 showed the SEM images of supported ILs catalysts. The morphology of mesoporous materials supports, and the supported ionic liquids exhibited similar and uniform morphology, which consisted of wellordered structures with the irregular surface and different sizes. The elemental composition of the suitable TiSBA-15@ILTsO was investigated by EDX (Fig. 4). The EDX analysis suggested that there existed the expected elemental signals. XPS spectra was also performed to examine the elemental composition and the chemical nature of the active species in the catalyst Ti-SBA-15@ILTsO. As shown in Fig. 5, the catalyst was composed of C, N, O, S, Si and Ti. The peaks corresponding to C1s, N1s, O1s, S2p, Si2p and Ti 2p appeared at 284.57 $\mathrm{eV}, 400.79 \mathrm{eV}, 532.45 \mathrm{eV}, 154.27 \mathrm{eV}, 101.91 \mathrm{eV}$ and $446.79 \mathrm{eV}$, respectively [34], which further verified the structure of the catalyst.

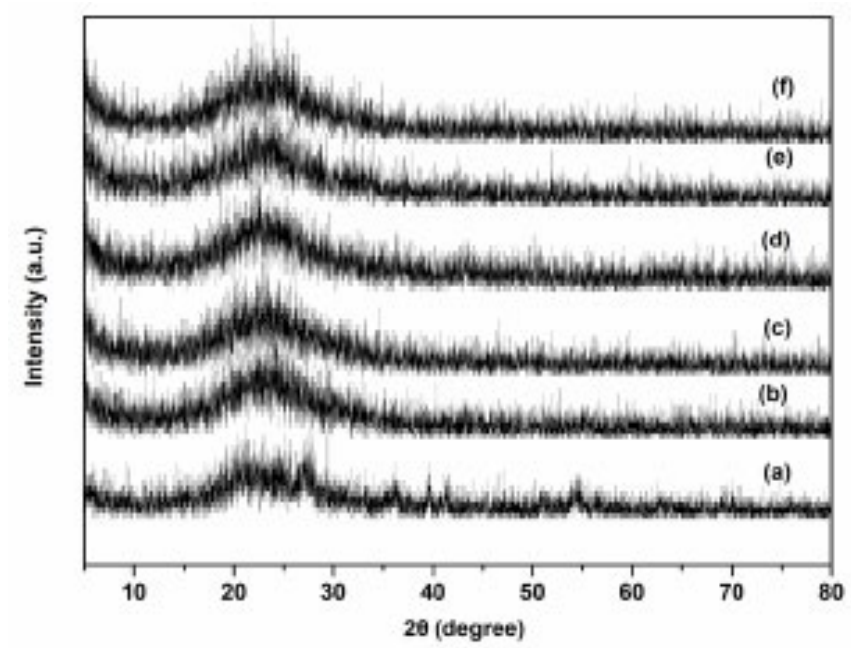

Fig. 2. XRD patterns of SBA-15@ILTsO (a), Ti-SBA-15@ILTsO (b), Al-SBA-15@ILTsO (c), Cu-SBA15@ILTsO (d), Co-SBA-15@ILTsO (e), Fe-SBA-15@ILTsO (f). 


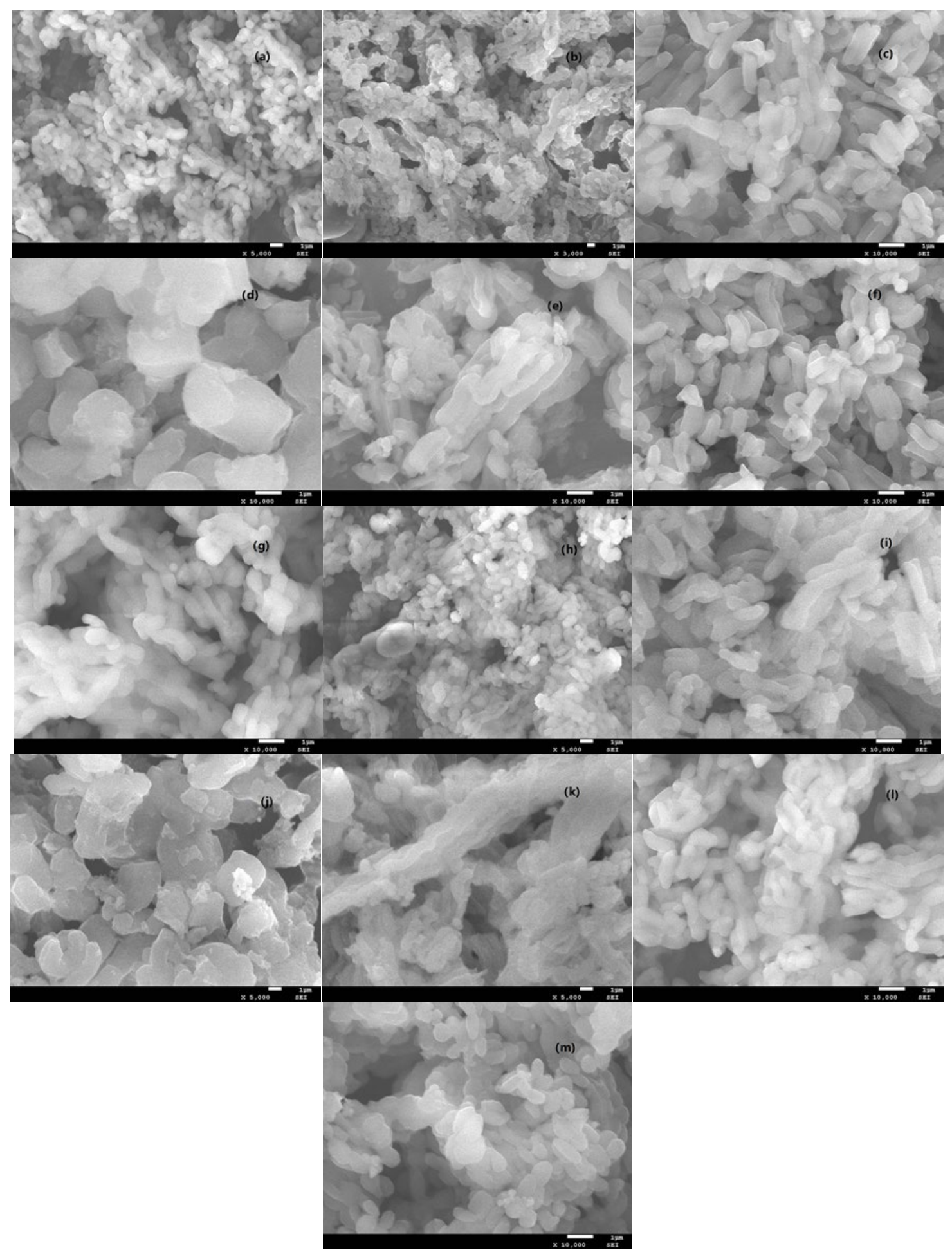

Fig. 3. SEM images of SBA-15@ILTsO (a), Ti-SBA-15@ILTsO (b), Al-SBA-15@ILTsO (c), Cu-SBA15@ILTsO (d), Co-SBA-15@ILTsO (e), Fe-SBA-15@ILTsO (f), SBA-15 (g), Ti-SBA-15 (h), Al-SBA-15 (i), Cu-SBA-15 (j), Co-SBA-15 (k), Fe-SBA-15 (l) and six times recovered Ti-SBA-15@ILTsO (m). 


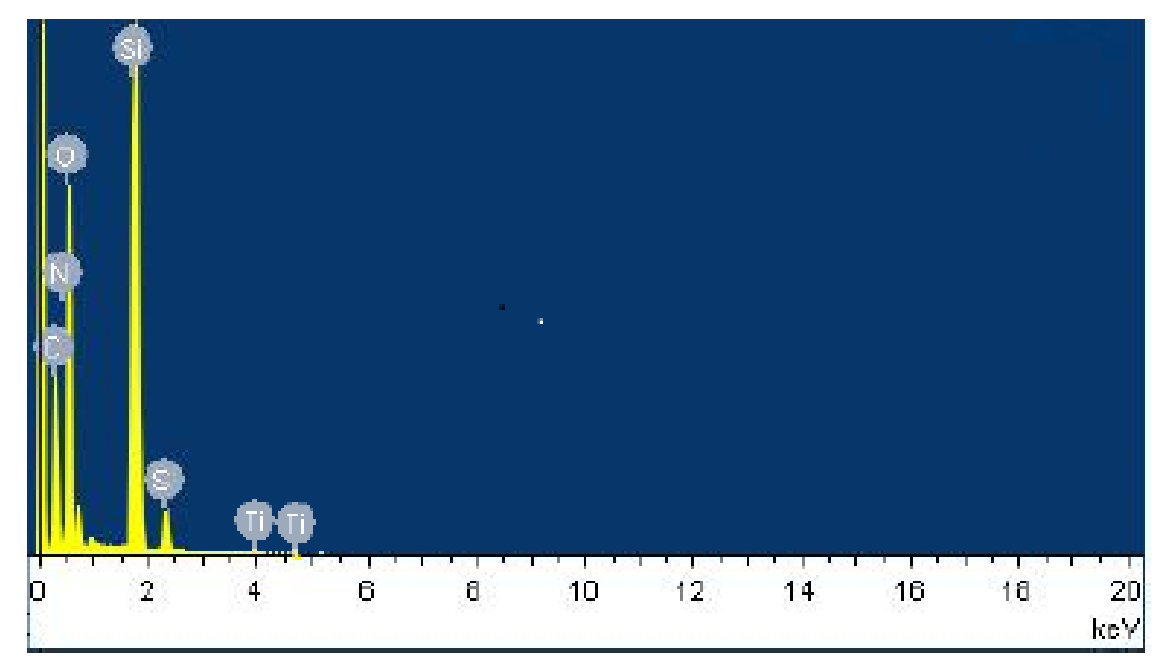

Fig. 4. EDX image of Ti-SBA-15@ILTsO.
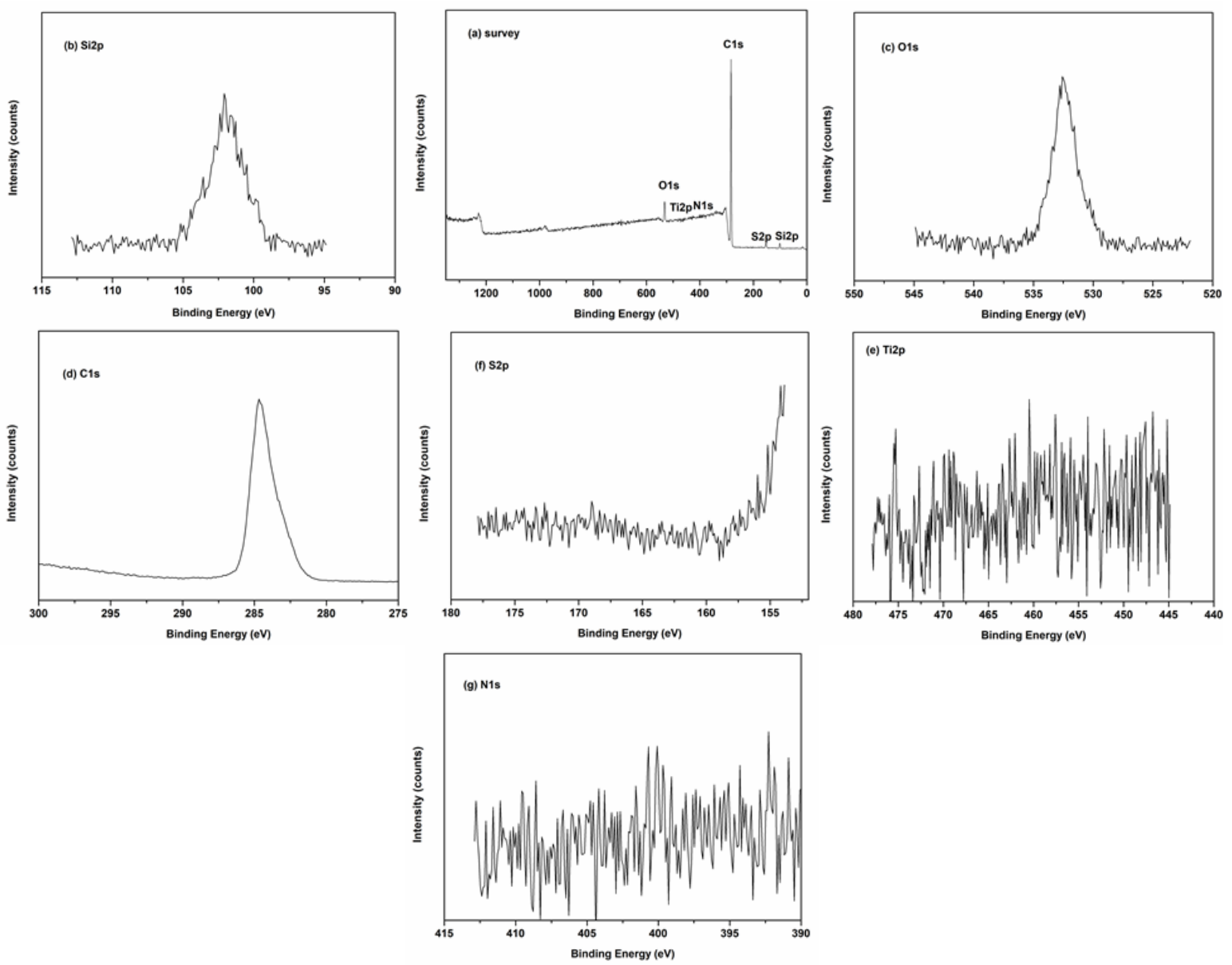

Fig. 5. XPS spectra of Ti-SBA-15@ILTsO (a) survey of the catalyst, (b) Si2p, (c) O1s, (d) C1s, (e) Ti2p, (f) S2p, (g) N1s. 
The BET analysis of Ti-SBA-15@ILTsO are shown in Fig. 6. Similarto other mesoporous materials, both Ti-SBA-15 and the catalyst Ti-SBA-15@ILTsO exhibited the type IV isotherms with H1 type hysteresis loop, which was took place in cylindrical pore openings of Ti-SBA-15 [35-38]. These behaviors reflected the mesoporous structure of Ti-SBA-15 and Ti-SBA-15@ILTsO materials, which indicated that titanium and ionic liquid sites modification did not cause these mesoporous materials construction collapse obviously. Following immobilization of ionic liquid in Ti-SBA-15 support displayed smaller surface area and pore volume, as well as slightly smaller pore size. It could be found that the surface area, pore volume and pore size were reduced from $507.9 \mathrm{~m}^{2} / \mathrm{g}, 0.6761 \mathrm{~cm}^{3} / \mathrm{g}$ and $5.90 \mathrm{~nm}$ for Ti-SBA-15 to $391.84 \mathrm{~m}^{2} / \mathrm{g}, 0.5722 \mathrm{~cm}^{3} / \mathrm{g}$ and $5.28 \mathrm{~nm}$ for TiSBA-15@ILTsO, respectively, which was due to the loading of IL sites on Ti-SBA-15 support.
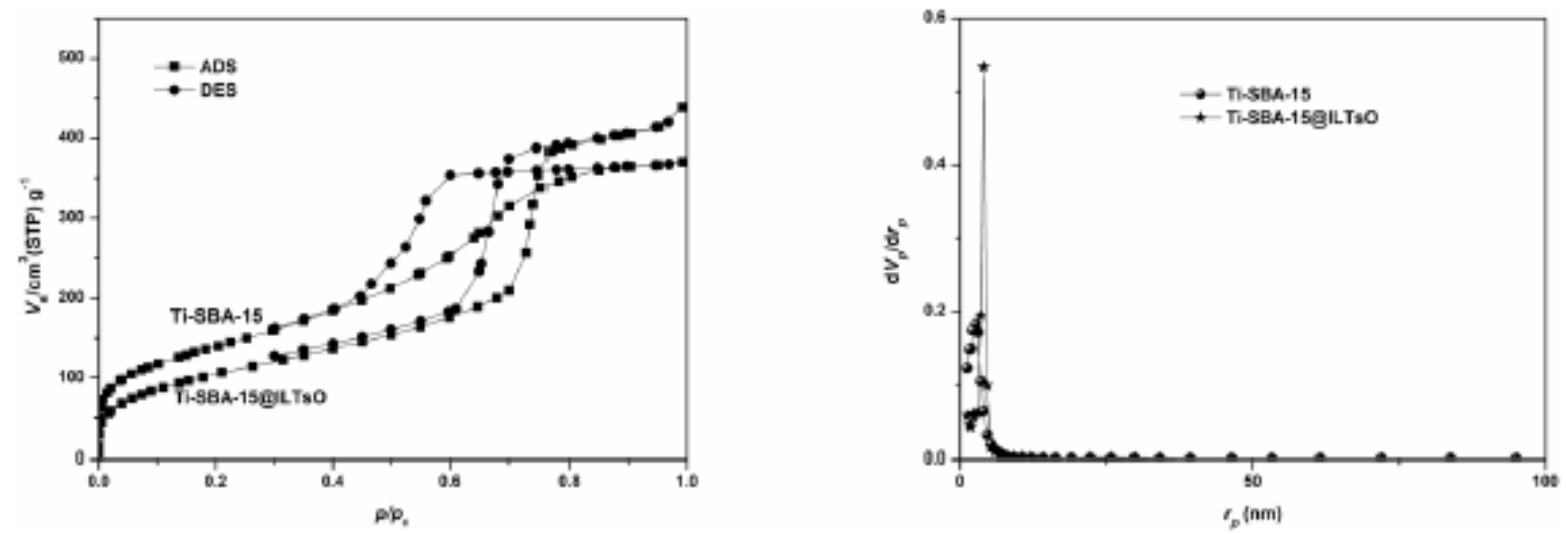

Fig. 6. $\mathrm{N}_{2}$ adsorption-desorption isotherms and pore size distributions of Ti-SBA-15@ILTsO and Ti-SBA-15.

Initially, the catalytic synthesis of 2,4,5-triphenyl- $1 H$-imidazole was as the model reaction for the optimization of reaction conditions (Table 1). It can be observed that the bulk ionic liquid ILTsO and solid supports as catalysts has only $9 \% \sim 61 \%$ yields of 2,4,5-triphenyl- $1 H$-imidazole, which suggested that ILTsO and solid supports showed bad catalytic activities (Table 1, entries 7-13). In addition, when catalyst was inexistence, no product was found at elevated temperature of $60^{\circ} \mathrm{C}$ and longer reaction time of $24 \mathrm{~h}$ (Table 1 , entry 14). However, the as-prepared supported ionic liquids could promote the catalytic process significantly, and drastic increase in the product yields were achieved at room temperature within shorter reaction times of 0.5 4 h (Table 1, entries 1-6). It was found that Ti-SBA-15@ILTsO demonstrated the highest catalytic performance and the product yield was $96 \%$ (Table 1, entry 5). Then, the effect of amount of best catalyst TiSBA-15@ILTsO was studied. Moderate to excellent yields were obtained from $0.2 \mathrm{~g}$ to $0.8 \mathrm{~g}$ (Table 1, entries 15-17 and 5). However, the amount of catalyst was further increased to $1.0 \mathrm{~g}$, no obvious enhancement of product yield was observed (Table 1, entry 18). The results showed that the supported ionic liquid Ti-SBA15@ILTsO has the highest catalytic activity even though with a low catalyst amount of $0.8 \mathrm{~g}$.

Table 1. Catalyst screening for synthesis of 2,4,5-triphenyl- $1 H$-imidazole. ${ }^{\mathrm{a}}$

\begin{tabular}{|c|c|c|c|c|}
\hline Entry & Catalyst & Catalyst (g) & Time (h) & Yield (\%) $^{\mathbf{b}}$ \\
\hline 1 & Cu-SBA-15@ILTsO & 0.8 & 3 & 88 \\
\hline 2 & Co-SBA-15@ILTsO & 0.8 & 2.5 & 75 \\
\hline 3 & Fe-SBA-15@ILTsO & 0.8 & 2 & 81 \\
\hline 4 & Al-SBA-15@ILTsO & 0.8 & 2 & 78 \\
\hline 5 & Ti-SBA-15@ILTsO & 0.8 & 0.5 & 96 \\
\hline 6 & SBA-15@ILTsO & 0.8 & 4 & 68 \\
\hline 7 & ILTsO & 1.0 & 5 & 61 \\
\hline 8 & Ti-SBA-15 & 1.0 & 5 & 57 \\
\hline 9 & Al-SBA-15 & 1.0 & 6 & 28 \\
\hline
\end{tabular}




\begin{tabular}{|c|c|c|c|c|}
\hline 10 & Co-SBA-15 & 1.2 & 6 & 25 \\
\hline 11 & Cu-SBA-15 & 1.0 & 5 & 48 \\
\hline 12 & Fe-SBA-15 & 1.2 & 6 & 37 \\
\hline 13 & SBA-15 & 1.2 & 24 & 9 \\
\hline 14 & - & $-^{c}$ & 24 & 0 \\
\hline 15 & Ti-SBA-15@ILTsO & 0.2 & 1 & 57 \\
\hline 16 & Ti-SBA-15@ILTsO & 0.4 & 1 & 79 \\
\hline 17 & Ti-SBA-15@ILTsO & 0.6 & 0.5 & 90 \\
\hline 18 & Ti-SBA-15@ILTsO & 1.0 & 0.5 & 96 \\
\hline
\end{tabular}

a Reaction conditions: benzaldehyde $(0.1 \mathrm{~mol})$, diphenylethanedione $(0.1 \mathrm{~mol})$, and ammonium acetate $(0.2$ $\mathrm{mol})$ were stirred in $\mathrm{EtOH}(30 \mathrm{~mL})$ at room temperature. ${ }^{b}$ Isolated yield. ${ }^{\mathrm{c}}$ Reaction temperature is $60{ }^{\circ} \mathrm{C}$.

The important indicator to measure the pros and cons for the design of catalyst is the stability evaluation of the catalyst Ti-SBA-15@ILTsO. As shown in Fig. 7, recycling catalytic experiments over TiSBA-15@ILTsO were carried out using the model reaction under the optimized conditions. The catalyst TiSBA-15@ILTsO was easily isolated by filtration and can be used directly for consecutive runs. Remarkably, Ti-SBA-15@ILTsO possessed a good reusability and maintained high catalytic performance at least six times without considerable reduction in catalytic activity. The product yield in the six run was $90 \%$, showing merely a $6 \%$ decrease in performance compared to the fresh catalyst. The stability for the designed catalyst Ti-SBA15@ILTsO was also confirmed by the thermal gravimetric analysis (Fig. 8). The first step of weight loss (2.58 $\%$ ) below $200{ }^{\circ} \mathrm{C}$ related to the removal of adsorbed water $\left(\leq 100{ }^{\circ} \mathrm{C}\right)$ and other volatile solvent residues $\left(100 \sim 200^{\circ} \mathrm{C}\right)$, whereas the main weight loss $(20.07 \%)$ from 200 to $600^{\circ} \mathrm{C}$ in the second step was corresponded to degradation of the organic moieties of ionic liquid. These observations demonstrated that the catalyst TiSBA-15@ILTsO is thermally stable below $200^{\circ} \mathrm{C}$. The recovered catalyst after six times has no obvious change in structure, referring to the FT-IR spectra in comparison with the fresh catalyst (Fig. 9). Furthermore, the recovered catalyst after six times has no obvious change in morphology (Fig. 3(m)). Hence, the good activity, stability and reusability of Ti-SBA-15@ILTsO made it possible for commercial applications.

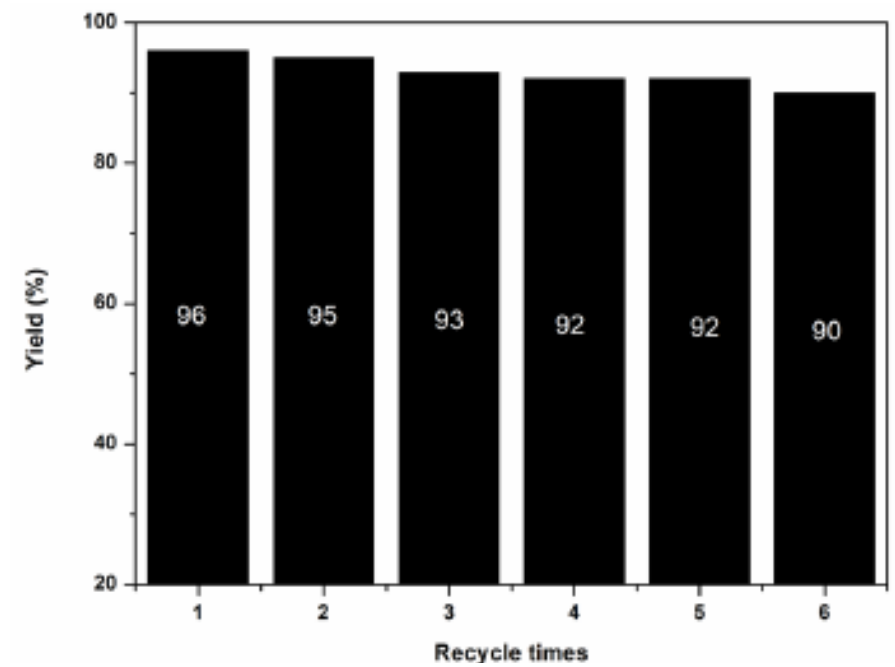

Fig. 7. The catalytic performance of reused Ti-SBA-15@ILTsO. 


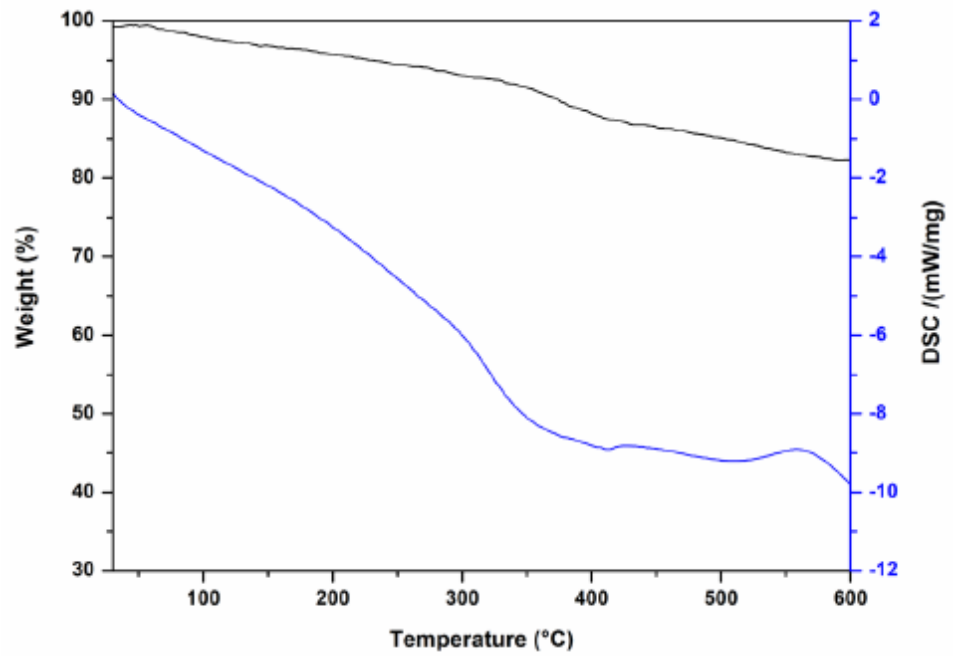

Fig. 8. Thermogravimetric analysis of Ti-SBA-15@ILTsO.

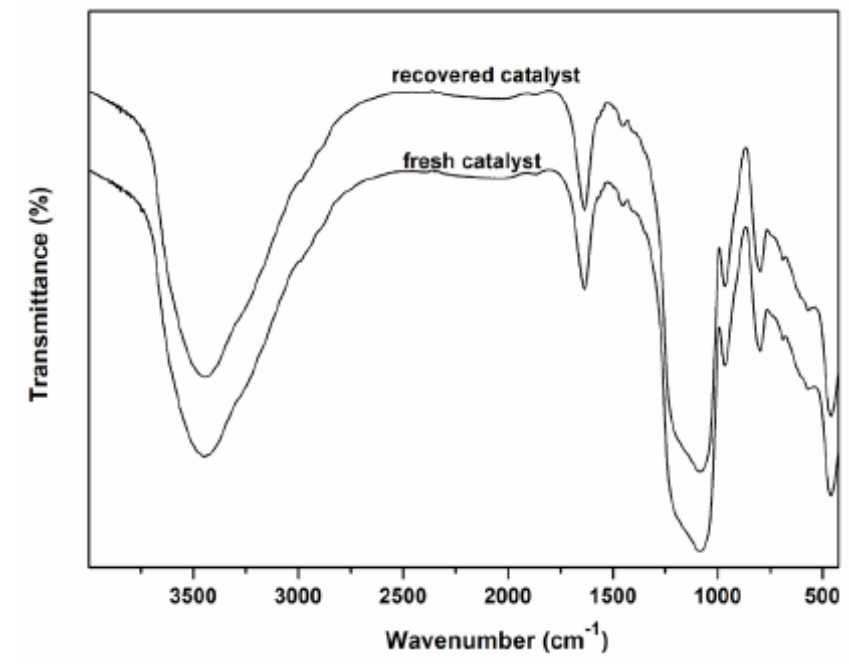

Fig. 9. FT-IR spectra of fresh and recovered catalyst.

After having the optimized conditions in hand, we explored the generality of our developed protocol by employing other aromatic aldehydes and the corresponding catalytic activities were showed in Table 2 . The corresponding 2,4,5-triaryl- $1 \mathrm{H}$-imidazoles were obtained in excellent yields $(92 \% \sim 99 \%)$ within $1 \mathrm{~h}$. The catalytic activities of aldehydes that contained electron donating groups (such as $\mathrm{CH}_{3}, \mathrm{OCH}_{3}, \mathrm{OH}$ ) (Table 2, entries 1-5) were higher than those of other aldehydes. When the structure of substitute containing electron withdrawing groups, it took longer time of $1 \mathrm{~h}$ to satisfy the excellent yields (Table 2, entries 6-10). 
Table 2. Catalytic synthesis of 2,4,5-triaryl- $1 H$-imidazoles. ${ }^{\text {a }}$

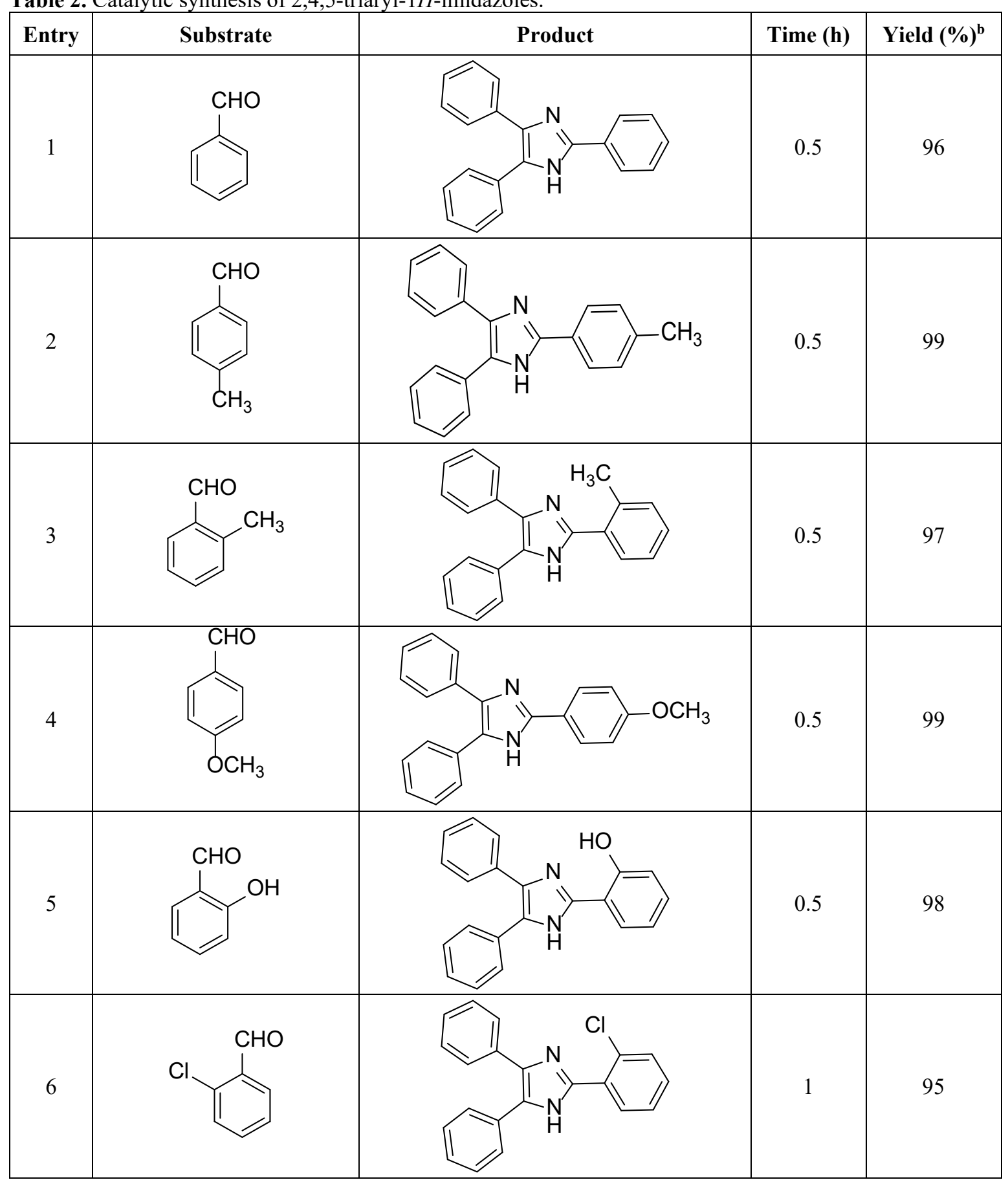




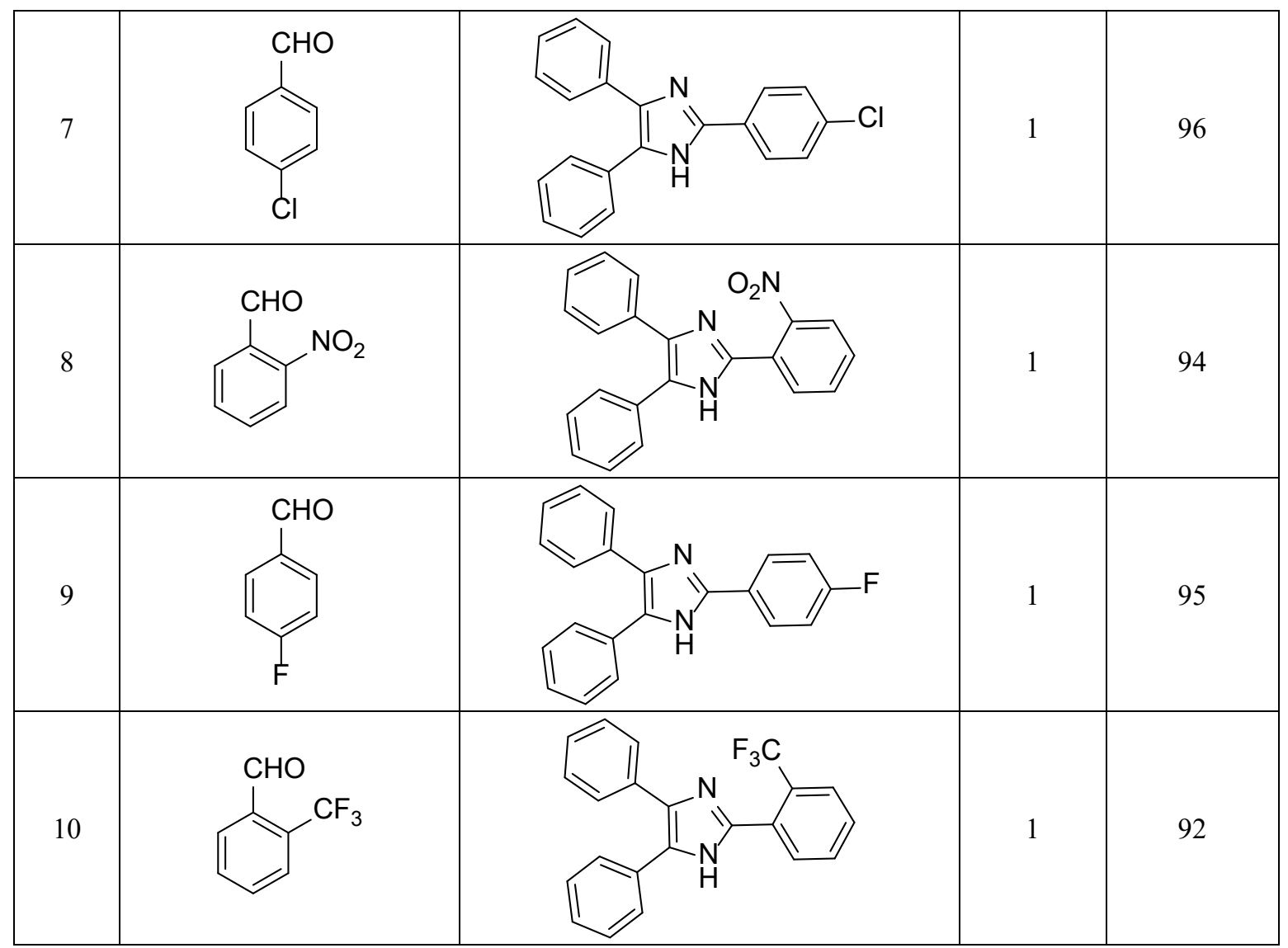

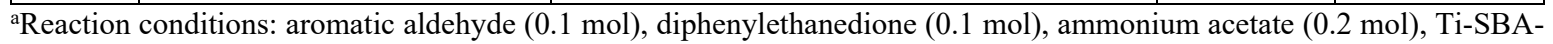
15@ILTsO $(0.8 \mathrm{~g})$ were stirred in $\operatorname{EtOH}(30 \mathrm{~mL})$ at room temperature. ${ }^{\mathrm{b}}$ Isolated yield.

Based on the above experimental results and related literature methods [15-20], a possible synergetic catalytic mechanism for the synthesis of 2,4,5-triaryl-1 $H$-imidazoles over Ti-SBA-15@ILTsO was proposed and presumed in Scheme 3. Firstly, benzyl was activated by the Ti sites of support through the polarization, and after that the nucleophilic attack of $\mathrm{N}$ atom led by NH4OAc for making the intermediate $\mathbf{A}$. The carbonyl of aryl aldehyde was also activated the $\mathrm{SO} 3 \mathrm{H}$ sites of ionic liquid and after that the nucleophilic attack of other $\mathrm{N}$ atom for the formation of imine. Simultaneously, Ti-SBA-15@ILTsO conducted a nucleophilic attack of imine on intermediate $\mathbf{A}$ and the intermediate $\mathbf{B}$ was formed. Afterwards, intermediate $\mathbf{C}$ was generated through the intramolecular nucleophilic effect. Ultimately, through loss of water and 2,4,5-triaryl- $1 H$-imidazoles was then produced along with the regeneration of catalyst for the next cycle. 


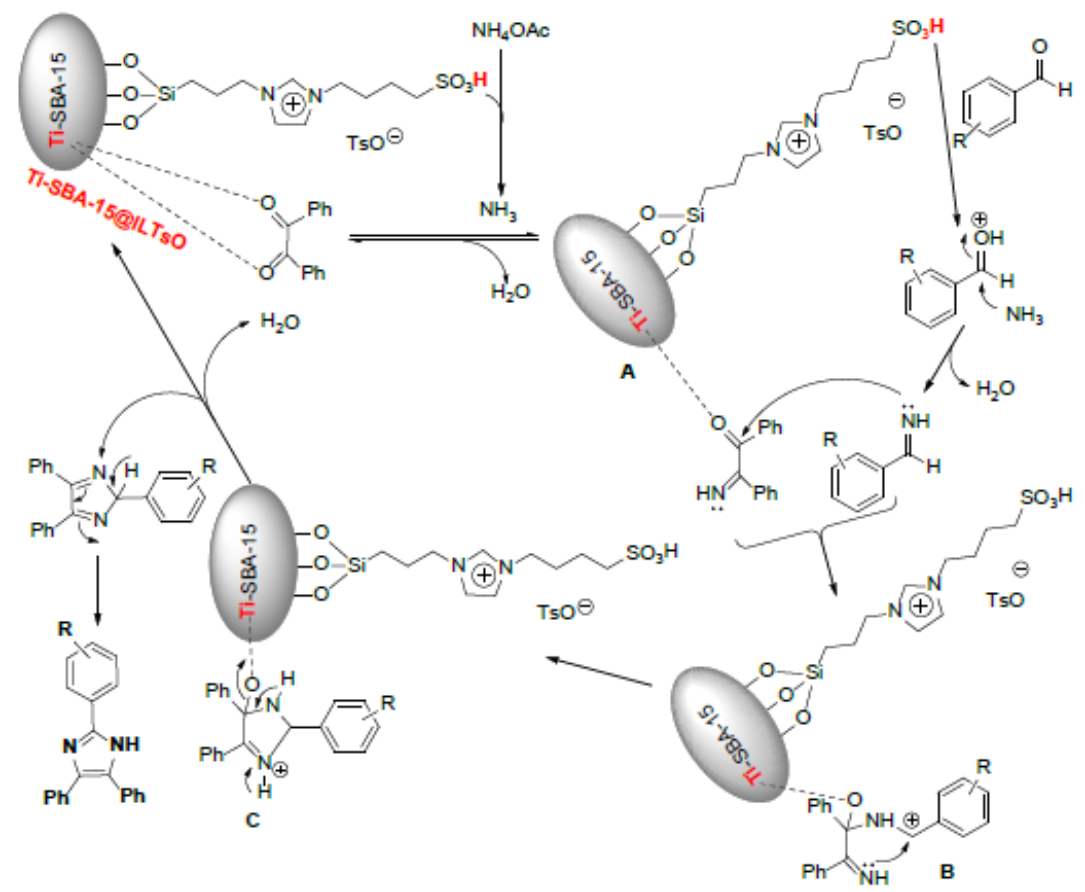

Scheme 3. Possible reaction mechanism for the synthesis of 2,4,5-triaryl- $1 H$-imidazoles.

\section{Conclusion}

In summary, a series of mesoporous materials $\mathrm{Ti}, \mathrm{Al}, \mathrm{Cu}, \mathrm{Co}$ and $\mathrm{Fe}$ incorporated SBA-15 supported ionic liquids were prepared and tested as catalysts for the synthesis of 2,4,5-triaryl- $1 H$-imidazoles. The experiment demonstrated that Ti incorporated SBA-15 supported ionic liquid catalyst Ti-SBA-15@ILTsO exhibited the highest activity with excellent product yields of $92 \% \sim 99 \%$ at room temperature. The multifunctional catalyst having full utilization of active sites can be easily recovered and reused for six times without considerable reduction in catalytic activity. The protocol was found to be advantageous in terms of high to excellent yields, mild reaction conditions, ease of isolation and reusability of the catalyst. This work provides a novel way for the design of highly efficient synergetic catalysts and expected to use to development of environmentally benign protocols for the synthesis of these products.

\section{Acknowledgements}

We gratefully acknowledge the 111 Project (D20015), National Natural Science Foundation of China (no. 21506115) and analysis and testing center of China Three Gorges University.

\section{References}

1. Shabalin, D. A.; Camp, J. E. Org. Biomol. Chem. 2020, 18, 3950-3964.

2. Ren, Z. L.; Cai, S.; Liu, Y. Y.; Xie, Y. Q.; Yuan, D.; Lei, M.; He, P.; Wang, L. J. Org. Chem. 2020, $85,11014-11024$. 
3. Wang, L.; Chen, H.; Zhang, N.; Liu, X.; Zheng, K. Tetrahedron Lett. 2021, 64, 152735.

4. Jin, X.; Chen, H.; Zhang, W.; Wang, B.; Shen, W.; Lu, H. Appl. Organometal. Chem. 2018, 32, e4577.

5. Hojati, S. F.; Nezhadhoseiny, S. A.; Beykzadeh, Z. Monatsh. Chem. 2013, 144, 387-390.

6. Reddy, M. V.; Jeong, Y. T. J. Fluorine Chem. 2012, 142, 45-51.

7. Munsur, A. Z. A.; Roy, H. N.; Imon, M. K. Arab. J. Chem. 2020, 13, 8807-8814.

8. Shaabani, A.; Afshari, R.; Hooshmand, S. E.; Nejad, M. K. ACS Sustain. Chem. Eng. 2017, 5, 95069516.

9. Jayram, J.; Jeena, V. RSC Adv. 2018, 8, 37557-37563.

10. Kumar, G.; Mogha, N. K.; Kumar, M.; Subodh, Masram, D. T. Dalton Trans. 2020, 49, 1963-1974.

11. Naeimi, H.; Aghaseyedkarimi, D. New J. Chem. 2015, 39, 9415-9421.

12. Allahresani, A.; Naghdi, E.; Nasseri, M. A. Inorg. Chem. Commun. 2020, 119, 108137.

13. Shaabani, A.; Afshari, R.; Hooshmand, S. E. New J. Chem. 2017, 41, 8469-8481.

14. Sangshetti, J. N.; Kokare, N. D.; Kotharkara, S. A.; Shinde, D. B. J. Chem. Sci. 2008, 120, 463-467.

15. Zarnegar, Z.; Safari, J. RSC Adv. 2014, 4, 20932-20939.

16. Waheed, M.; Ahmed, N.; Alsharif, M. A.; Alahmdi, M. I.; Mukhtar, S. ChemistrySelect 2017, 2, 79467950.

17. Nguyen, T. T.; Le, N. P. T.; Nguyen, T. T.; Tran, P. H. RSC Adv. 2019, 9, 38148-38153.

18. Kumar, D.; Kommi, D. N.; Bollineni, N.; Patel, A. R.; Chakraborti, A. K. Green Chem. 2012, 14, 2038-2049.

19. Vinoth, G.; Indira, S.; Bharathi, M.; Archana, G.; Alves, L. G.; Martins, A. M.; Bharathi, K. S. Inorg. Chim. Acta 2021, 516, 120089.

20. Pervaiz, S.; Mutahir, S.; Ullah, I.; Ashraf, M.; Liu, X.; Tariq, S.; Zhou, B. J.; Khan, M. A. Chem. Biodivers. 2020, 17, e1900493.

21. Nordness, O.; Brennecke, J. F. Chem. Rev. 2020, 120, 12873-12902.

22. Hu, Y.; Zhang, R. L.; Fang, D. Environ. Chem. Lett. 2019, 17, 501-508.

23. Itoh, T.; Takagi, Y. ACS Sustain. Chem. Eng. 2021, 9, 1443-1458.

24. Tapia, M. G.; Montes, A. C.; Morcillo, E. M.; Huguet, M. T. G.; de Torres, N. H. W.; Ríos R. C. J. Mex. Chem. Soc. 2014, 58, 16-21.

25. Doherty, A. P.; Patterson, S.; Diaconu, L.; Graham, L.; Barhdadi, R.; Puchelle, V.; Wagner, K.; Office, D. L.; Chen, J.; Wallace, G. G. J. Mex. Chem. Soc. 2015, 59, 263-268; Guerrero R. L.; Rivero, I. A. J. Mex. Chem. Soc. 2012, 56, 201-206.

26. Banothu, J.; Gali, R.; Velpula, R.; Bavantula, R. Arab. J. Chem. 2017, 10, S2754-S2761.

27. Hilal, D. A.; Hanoon, H. D. Res. Chem. Intermed. 2020, 46, 1521-1538.

28. Fehrmann, R.; Riisager, A.; Haumann, M. Supported ionic liquids: Fundamentals and applications, Wiley-VCH, Weinheim, 2014; Mohamedali, M.; Ibrahim, H.; Henni, A. Micropor. Mesopor. Mater. 2020, 294, 109916.

29. Gupta, R.; Yadav, M.; Gaur, R.; Arora, G.; Yadav, P.; Sharma, R. K. Mater. Horiz. 2020, 7, 30973130.

30. Sudarsanam, P.; Zhong, R.; den Bosch, S. V.; Coman, S. M.; Parvulescu, V. I.; Sels, B. F. Chem. Soc. Rev. 2018, 47, 8349-8402.

31. Yao, N.; Chen, C.; Li, D. J.; Hu, Y. L. J. Environ. Chem. Eng. 2020, 8, 103953.

32. Kukawka, R.; Pawlowska-Zygarowicz, A.; Dzialkowska, J.; Pietrowski, M.; Maciejew, H.; Bica, K.; Smiglak, M. ACS Sustain. Chem. Eng. 2019, 7, 4699-4706.

33. Dhar, A.; Kumar, N. S.; Khimani, M.; Al-Fatesh, A. S.; Ibrahim, A. A.; Fakeeha, A. H.; Patel, H.; Vekariya, R. L. RSC Adv. 2020, 10, 15282-15292. 
34. Verma, P.; Kuwahara, Y.; Mori, K.; Raja, R.; Yamashita, H. Nanoscale 2020, 12, 11333-11363; Awoke, Y.; Chebude, Y.; Márquez-Álvarez, C.; Díaz, I. Catal. Today 2020, 345, 190-200; Wang, S.; Li, Z.; Yi, W.; Fu, P.; Zhang, A.; Bai, X. Renew. Energy 2021, 163, 1673-1681; Miao, K.; Luo, X.; Wang, W.; Guo, J.; Guo, S.; Cao, F.; Hu, Y.; Chang, P.; Feng, G. Micropor. Mesopor. Mater. 2019, 289, 109640; Ruchomski, L.; Pikus, S.; Pikula, T.; Mączka, E.; Kosmulski, M. Colloid. Surface. A 2020, 599, 124922.

35. Dokhaee, Z.; Ghiaci, M.; Farrokhpour, H.; Buntkowsky, G.; Breitzke, H. Ind. Eng. Chem. Res. 2020, $59,12632-12644$.

36. Huang, Y.; Zheng, K.; Liu, X.; Meng, X.; Astruc, D. Inorg. Chem. Front. 2020, 7, 939-945.

37. Chatterjee, S.; Bhaduri, K.; Modak, A.; Selvaraj, M.; Bal, R.; Chowdhury, B.; Bhaumik, A. Mol. Catal. 2021, 502, 111381.

38. Ziarani, G. M.; Rohani, S.; Ziarati, A.; Badiei, A. RSC Adv. 2018, 8, 41048-41100.

39. Verma, P.; Kuwahara, Y.; Mori, K.; Raja, R.; Yamashita, H. Nanoscale 2020, 12, 11333-11363. 